\title{
Intensifying the use of benefit sanctions: an effective tool to increase employment?
}

\author{
Bernhard Boockmann 1,2,3* , Stephan L. Thomsen ${ }^{4,5,6 \dagger}$ and Thomas Walter $4,6,7 \dagger$
}

\author{
*Correspondence: \\ bernhard.boockmann@iaw.edu \\ ${ }^{\dagger}$ Equal contributors \\ 1 Institute for Applied Economic \\ Research (IAW), Ob dem \\ Himmelreich 1, D-72074, Tübingen, \\ Germany \\ ${ }^{2}$ Universität Tübingen, Tübingen, \\ Germany \\ Full list of author information is \\ available at the end of the article
}

\begin{abstract}
In Germany, imposition of benefit cuts for non-compliant welfare recipients depends on the policy of the local welfare agencies resulting in considerable regional variation, expressed in milder and stricter sanction regimes. Findings from international studies show, that benefit sanctions can substantially increase individual employment uptake. This raises the question, whether a stricter use of sanctions will be effective in Germany. We analyze this question by exploiting the variation of regional sanction regimes as instrumental variables to estimate the LATE of sanctions on the individual employment probability. A tighter sanction policy can be quite effective for non-compliant welfare recipients.
\end{abstract}

JEL codes: 138; J64; C31

Keywords: Benefit sanctions; Welfare recipients; IV; LATE

\section{Introduction}

Benefit sanctions are used as part of the unemployment insurance and public welfare systems in many countries. Social welfare benefits have increasingly been made conditional on requirements such as active search for a job or participation in active labor market programs. ${ }^{1}$ Sanctions (or the threat to impose them) are intended to provide incentives for benefit recipients to comply with these requirements. The empirical literature on the effects of sanctions shows that benefit cuts often increase transitions from unemployment to employment. ${ }^{2}$ Yet, the strictness of sanctions differs considerably across countries, and there is no country that imposes sanctions for a first refusal of a job offer or a labor market program automatically (see Venn 2012). Tightening the sanction regime, therefore, is a relevant policy option. Given the evidence for sanction effects at the individual level, the question arises whether an intensified use of benefit sanctions would be effective. This question has not been investigated in the literature so far.

To answer the question, we make use of a unique data set for Germany. The case of Germany is interesting because sanctions have become much more commonplace after the reform of the German welfare system in 2005. The obligation to actively search for employment and to participate in active labor market policy programs marked an important change in Germany's welfare policy. For the first time, welfare recipients had become a target group of labor market activation. Benefit sanctions are now frequently imposed

(C2014 Boockmann et al.; licensee Springer. This is an Open Access article distributed under the terms of the Creative Commons Attribution License (http://creativecommons.org/licenses/by/4.0), which permits unrestricted use, distribution, and reproduction in any medium, provided the original work is properly credited. 
by welfare agencies in the form of a partial or a complete revocation of benefits for a certain period of time. Welfare agencies possess a high degree of discretion in individual sanction decisions, which results in substantial regional variation of sanction rates. While in some regions sanctions are imposed frequently, they are used rarely in other regions. ${ }^{3}$

Exploiting this regional variation, we follow an instrumental variable approach using information about sanctions across welfare agencies to identify the effect a stricter sanction policy would have. ${ }^{4}$ The data set for the empirical analysis combines information of a large survey of welfare benefits recipients with administrative information, collected at 154 welfare agencies in Germany. In addition to individual information, the data provide information on organizational aspects and strategies of the welfare agencies. In particular, we have access to survey information on the sanction strategy that is used in the respective welfare agency. The different sanction strategies of the welfare agencies as well as the differences in the frequency with which sanctions are actually imposed are used to instrument the selection process at the individual level and to estimate local average treatment effects (LATE, see Imbens and Angrist (1994)). Specifically, we estimate the effect of a sanction on individuals who are not sanctioned in a welfare agency with a moderate sanction policy, but who would be sanctioned if the agency would change its policy and would impose sanctions more frequently. The estimated LATEs can thus be interpreted as a measure of the effectiveness of an intensified use of benefit sanctions.

The remainder of this paper is organized as follows. Section 2 presents some details of the German welfare system and the institutional setting of benefit sanctions. The data used in the empirical analysis is described in Section 3. Our empirical identification strategy is discussed in Section 4. In Section 5, we provide the estimation results and the final section concludes.

\section{The German welfare system and its sanction scheme}

The German welfare system was substantially reformed at the beginning of 2005, when the so-called unemployment benefits II (UBII) were introduced which replaced the former unemployment assistance and social assistance. UBII are means-tested benefits that do not depend on former earnings and cover some direct cash payments and compulsory social insurance contributions and costs of housing. Additional expenses for special needs may also be covered. The means-test takes into account the wealth and income of all individuals living in the household. ${ }^{5}$ In order to be eligible for UBII, persons have to be aged between 15 and 64 years and be able to work for at least 15 hours per week. It is important to note that unemployment is not a prerequisite for receipt of UBII. Individuals who are employed but whose household income is too low are also eligible for UBII. Claimants capable of work have to register with the local welfare agency and are obliged to participate in active labor market policy programs. UBII recipients' rights and duties in the activation process are set out in a so-called 'integration contract' (Eingliederungsvereinbarung), an agreement between the welfare agency and the benefit recipient containing obligations with respect to program participation and job search activities as well as detailing the services provided by the welfare agency. The integration contract is usually set up after the first meeting of a UBII recipient with the caseworker. 
The caseworker counsels and advises the UBII recipient and decides about placement in active labor market programs. If the caseworker detects non-compliance of the UBII recipient, the welfare agency is legally required to impose a sanction by benefit revocation (Chapters 31, 31a, 31b and 32 of Book II of the German Social Code). However, there is discretion at the agency level whether a sanction is actually imposed or not. All UBII recipients are informed about the possibility of sanctions in the integration contract and each time they are assigned to a program. Yet, there is no formal warning process when a non-compliance is detected. Although a hearing of the benefit recipient is formally required before the imposition of a sanction, there is evidence that this requirement is not implemented in practice as reported by Baethge-Kinsky et al. (2007). Hence, the welfare agency may immediately impose a sanction. Sanctions have a duration of three months and can be imposed for various reasons. For minor non-compliances, such as the failure to properly report on job search activities to the welfare agency or not showing up for an appointment with the caseworker, benefits are cut by $10 \%$. More severe infringements (lack of job search effort, refusal to accept a suitable job offer, refusal to participate in a program) lead to a benefit reduction of $30 \%$. In case of repeated incidents of severe infringements within one year, a second $(60 \%$ cut) or a third sanction $(100 \%$ cut $)$ can be imposed. A similar possibility exists in the case of repeated minor non-compliances, where sanctions can be increased gradually by $10 \%$ up to a cut of $100 \%$. For UBII recipients below 25 years of age, benefits can be reduced by $100 \%$ even for the first incident of non-compliance.

\section{Data}

The empirical analysis is based on a unique data set that combines various different data sources. The core of these data is a survey of UBII recipients who received benefits in October 2006 or entered UBII receipt in the second half of 2006. These individuals were randomly sampled from the administrative records of the Federal Employment Agency (FEA). The survey was conducted in 154 out of 439 German welfare agencies (see Additional file 1: Figure S1 for an illustration of the sampled agencies). In each of the agencies, between 100 and 300 computer-assisted telephone interviews were conducted in the beginning of 2007 (January to April). In total, 24,563 interviews were realized. The surveyed data include individual characteristics (e.g. gender, age, marital and parent status, education, health and disability status, migration background), information on other household members (number, age and relation to the respondent) and details concerning the labor market status and history (current labor market state, former spells of insured and minor employment, former spells of unemployment, UBII receipt, participation in active labor market policy programs). Moreover, the survey provides information about basic skills (for example reading, writing, math and computer skills), further qualifications (e.g. driver's license), job search activities and information about benefit sanctions.

Importantly, respondents were asked whether they have ever been sanctioned by their welfare agency, and, if so, in which month the last sanction was imposed. We use this information to construct our treatment variable and define those individuals as treated, who report having been sanctioned for the first time and only once between October 2006 and April 2007. Since we focus on the effect of the first sanction imposed, persons with 
previous sanctions are deleted from the estimation sample. The reason is that the second and further sanctions could be the outcome of a previous (ineffective) sanction; this dependence would have to be dealt with in an explicitly dynamic framework. In general, focusing on the first treatment event is a standard way of dealing with repeated entries into treatment Sianesi (2004). Individuals who explicitly state that they have been sanctioned before the sampling date are dropped from the data for the same reason. ${ }^{6}$ We only consider the event of a sanction as a binary indicator, since precise information on the level of the benefit cut is not available. We restrict our analysis to individuals aged 18 to 57 , who were unemployed at the beginning of their respective UBII spell. Individuals aged 58 or above can opt for the so-called relieved benefit entitlement. Within this scheme they are no longer required to actively search for employment, but remain on welfare benefits until retirement age. Individuals aged 15 to 17 are subject to compulsory schooling and cannot be expected to take up employment. The estimation sample contains 15,361 observations. $^{7}$

Information on the outcome of interest (employment) is taken from administrative data of the FEA. These administrative data contain labor market states on a monthly basis for each individual up to October 2007, which allows to follow each sanctioned person for at least six months after the imposition of the sanction. For a person sanctioned in January 2007, for example, we examine the labor market states from February to July 2007, for a person sanctioned in April 2007, information on the period from May to October 2007 is used.

In order to compare the sanctioned individuals with the control group, we constructed a hypothetical sanction date for each non-sanctioned individual by drawing randomly from a uniform distribution of sanction dates from the period of October 2006 to April 2007 , i.e. the probability of receiving a (hypothetical) sanction in each of these months is assumed to be $1 / 7$. Given this (hypothetical) sanction date, the non-sanctioned group is followed for six months as well. ${ }^{8}$ The economic conditions during the observation period were quite favorable. In 2006, German GDP grew by $2.9 \%$ and in 2007 by $2.5 \%$. However, while the number of unemployment insurance benefit recipients decreased strongly in 2007 (yearly average of 1.253 million recipients in 2007 compared to 1.664 million in 2006), there was almost no decline in the number of UBII recipients (5.277 million in 2007 compared to 5.392 million in 2006). ${ }^{9}$

The combined administrative and survey data were linked to additional data at the agency level collected via surveys and case studies in all 154 sampled agencies in 2006 and 2007. These data include information to characterize the welfare agencies' organizational structure and their strategies for the activation of UBII recipients (for example the number and qualification of caseworkers, type of case management, counseling concept, placement approach, mix of active labor market policies, sanction strategy). Furthermore, regional information was added reflecting labor market conditions, which includes indicators for high regional unemployment, high GDP per capita and high welfare dependence ratios (in each case, indicating a value higher than the third quartile of the distribution of the respective variable across all German welfare agencies). The regional information was measured in December 2003. The welfare ratio refers to former social assistance recipients only. It does not include former unemployment assistance recipients. Moreover, two variables reflecting respondents' place of residence (city district vs. rural area, East vs. West Germany) were included. 


\section{Estimation approach}

\subsection{The LATE estimator}

For the identification of the effect of a sanction on employment, consider the linear probability model:

$$
Y_{i}=X_{i} \beta+S_{i} \theta+u_{i}
$$

where $Y_{i}$ is the binary outcome variable of interest (for example, $Y_{i}=1$ denotes employment of individual $i$ and $Y_{i}=0$ denotes non-employment), $X_{i}$ is a vector of covariates (at individual and regional/agency level) and $S_{i}$ is a dummy variable indicating whether individual $i$ has been sanctioned $\left(S_{i}=1\right)$ or not $\left(S_{i}=0\right)$. Under the additional assumption that the error term $u_{i}$ has zero mean conditional on all covariates $X_{i}$ and $S_{i}$, one could apply simple OLS estimation to identify the effects of the right-hand side variables on $Y_{i}$. However, we cannot rule out that $S_{i}$ is endogenous in our case, i.e. it may be that $\operatorname{Cov}\left(S_{i}, u_{i}\right) \neq 0$. In this case an OLS estimate of the sanction effect on $Y_{i}$ would be biased. Endogeneity of $S_{i}$ could be due to different reasons. For example, there could be a negative selection process driven by motivation or other unobservable factors such that individuals with unfavorable characteristics are sanctioned with higher probability. As a result, the OLS estimate of the effect of $S_{i}$ on $Y_{i}$ would be underestimated. However, there could also be a positive selection process initiated by caseworkers if those with unfavorable characteristics are not activated and thus not sanctioned. A positive selection of this kind would result in an overestimated effect of $S_{i}$ on $Y_{i}$. Hence, the bias of a simple OLS estimation is undetermined ex-ante.

To overcome the potential endogeneity of $S_{i}$, we use an instrumental variable approach to estimate the sanction effect on the outcome variable $Y_{i}$. Specifically, we consider a binary instrument $Z$ such that the first stage equation of a two-stage least squares estimator can be written as:

$$
S_{i}=Z_{i} \delta+X_{i} \alpha+\epsilon_{i}
$$

where $X_{i}$ is the same vector of covariates as in Equation 1 and $\epsilon_{i}$ is an error term with zero conditional mean. We allow the error terms $\epsilon_{i}$ and $u_{i}$ to be correlated across observations from the same agency. Under this specification, the two-stage least squares estimator provides an estimate of $\theta$ in Equation 1 that can be interpreted as a local average treatment effect (LATE, see Imbens and Angrist (1994)). It measures the impact of a benefit cut on those individuals, who get a sanction when $Z$ changes its value from 0 to 1 . For the instrument $Z$, we use two different variables:

1. the sanction strategy of welfare agencies as reported by the agency managers (denoted as $Z_{1}$ ) and

2. the actually observed sanction rate within the agencies (denoted as $Z_{2}$ ).

Welfare agencies play a crucial role for the use of sanctions, since they have substantial discretion. Whether or not a sanction is actually imposed, depends not only on the detected infringement, but also on the general sanction policy of the welfare agency. Some 
agencies have a high affinity for sanctions, while other agencies are more reserved. An important element for the agencies' management in implementing a strategy is the definition of local guidelines (verhaltenslenkende Weisungen) for caseworkers. These guidelines are issued to control caseworker behavior in general. Specifically, in some agencies they may be used in order to induce caseworkers to impose sanctions frequently. Other welfare agencies might follow a milder sanction policy and refrain from encouraging or even discourage caseworkers from imposing sanctions. Therefore, the sanction strategy influences caseworkers' actions and, consequently, creates variation in the use of sanctions across welfare agencies.

In the surveys and case studies at agency level described in Section 3, agency managers were asked about the use and importance of sanctions within their agencies. The answers of managers were classified as depicted in Table 1. The distribution of answers makes clear that benefit sanctions are valued differently across welfare agencies. While 41 of the 154 agencies in our sample use sanctions only to comply with legal requirements, other agencies either apply sanctions more frequently, perhaps even when minor noncompliances of clients are detected, or less frequently, so that not all infringements are punished. The agency will therefore have an impact on the individual probability of being sanctioned.

Option a) of Table 1 differentiates between agencies that strategically impose sanctions with high incidence as opposed to agencies that do not. We use this differentiation to specify our first instrument $Z_{1}$, which has value one if an individual is registered at an agency that frequently imposes sanctions as part of its activation strategy and which is zero otherwise, i.e. if the welfare agency is classified into one of the options b) to g) of Table 1. Using $Z_{1}$ as an instrument, the estimate of $\theta$ depicts the LATE of a sanction on those individuals who are sanctioned in an agency that frequently imposes sanctions and who would not be sanctioned in another (more reserved) agency. In other words, it measures the impact of a sanction on those individuals who would be sanctioned if the welfare agency decided to change its sanction strategy from a more reserved one to a strict one. Thus, this LATE can be interpreted as an estimate of a more intensive use of sanctions.

For our alternative instrument $Z_{2}$, we make use of the actually observed sanction rates within the agencies. The sanction rate of an agency is defined to be the share of individuals registered at the respective agency who received a benefit cut between October 2006 and April 2007. To obtain a binary instrument, we differentiate between agencies with a sanction rate above the median $\left(Z_{2}=1\right)$ and agencies with a sanction rate below the median $\left(Z_{2}=0\right)$. Under this specification, we estimate the LATE of a sanction on those individuals, who would be sanctioned, if the agency decided to increase the sanction rate

Table 1 The use of sanctions in welfare agencies (number of agencies in brackets)

\begin{tabular}{lll}
\hline a) & Sanctions are part of the activation strategy and applied frequently & (32) \\
b) & Sanctions are supported but are not part of the activation strategy & (41) \\
c) & Sanctions are used to comply with legal requirements & $(41)$ \\
d) & Sanctions are regarded sceptically, but nevertheless are used & (12) \\
e) & Sanctions have no special role (neither positively nor negatively) & (5) \\
f) & Sanctions are rarely used & Sanctions are used for general monitoring purposes, but are not regarded as useful in single cases \\
g)
\end{tabular}


from below to above the median level. Again, this effect can be interpreted as an estimate of a more intensive use of sanctions.

No matter which instrument $Z$ is used, the identification of a LATE depends on three conditions:

1. $Z$ is a valid instrument, i.e. $\operatorname{Cov}\left(Z_{i}, u_{i}\right)=0$ and $Z_{i}$ is partially correlated with $S_{i}$ once it is controlled for $X_{i}$.

2. The probability of being sanctioned changes with the value of $Z$.

3. Monotonicity: Individuals that are sanctioned in agencies of the type $Z=0$ must also be sanctioned in agencies of the type $Z=1$. And those individuals who are not sanctioned under $Z=1$ should not be sanctioned under $Z=0$ either.

\subsection{Plausibility of the LATE assumptions}

In the following, we discuss these conditions referring to instrument $Z_{1}$, the sanction strategy of welfare agencies. A similar reasoning also applies for instrument $Z_{2}$. The monotonicity assumption (condition 3) is not testable (see Imbens and Angrist (1994), p. 469), but it is very likely to hold in our case due to the distinction of more and less severe infringements in the German Social Code (see Section 2 above). If a sanction is imposed on an individual who is registered at an agency which rarely uses sanctions, the non-compliance must have been severe and should also be punished in an agency that uses sanctions frequently. Similarly, if an agency that sanctions frequently does not have a reason to sanction an individual for a particular infringement, an agency which rarely uses sanctions should not have a reason, either. Condition 2) is also satisfied. As will be shown in more detail in Section 5, the sanction rate is indeed larger in agencies that frequently impose sanctions as part of their activation strategy. Therefore, the probability of an individual getting a sanction increases when $Z_{1}$ changes its value from zero to one.

Condition 1), $\operatorname{Cov}\left(Z_{1}, u_{i}\right)=0$, requires, that $Z_{1}$ has no direct effect on $Y_{i}$. A direct effect would exist if individuals changed their behavior due to the actual realization of $Z_{1}$. This, however, can be perceived to be highly unlikely. The welfare agency's sanction strategy is not communicated to its clients. Hence, individuals do not know whether or not sanctions are used more frequently in their agency than in another agency. They therefore lack information to draw comparisons with other agencies, whose strategies are even more difficult to find out. Thus, there should not be any behavioral response of individuals to the sanction strategy of the welfare agency.

A possible counterexample is provided by Lalive et al. (2005) and Arni et al. (2013). For the Swiss case, these authors argue that monitoring intensity and warnings may have a positive effect on the exit rate from unemployment, independently of actual sanctions being imposed. If monitoring intensity and warnings are associated with higher sanction intensity, it would be difficult to identify the effect of actual sanctions without information on monitoring and warnings. It may appear that a positive association is not unlikely, as a first infraction may result in an informal warning and only the second or later infraction in an actual sanction if the agency pursues a tough sanction strategy. However, the practice of imposing sanctions in Germany differs from the Swiss case. There is no formal warning process when non-compliance is detected. Thus, the degree of caseworker discretion is higher and warnings may or may not be given only informally. The qualitative 
study by (Baethge-Kinsky et al. (2007): 52) suggests that informal warnings are used regularly but remain an abstract threat and are followed by the imposition of a sanction only in relatively few cases. As a consequence, it appears that UBII recipients can learn little about their agency's sanction policy from informal warnings given during the monitoring process.

If UBII recipients were aware of the sanction strategies of the agencies, the only way to avoid a tough sanction regime for a (non-cooperative) person registered at an agency that frequently imposes sanctions would be to move to another region, since individuals are forced to register with the agency at the place of residence. However, financial constraints are likely to prevent UBII recipients from moving. In addition, welfare agencies are quite reluctant to support a move, since they would have to pay (most of) the costs.

It is also unlikely that the socio-demographic composition of the UBII recipients or the labor market situation drives an agency to adopt a certain sanction strategy. To check this, we have predicted the instrument propensity scores based on the variables considered in the first stage regressions. ${ }^{10}$ The instrument propensity score depicts the probability of the instrumental variable to become 1 , i.e. $\operatorname{Pr}\left(Z_{j}=1 \mid X\right)$ with $j \in$ $\{1,2\}$. Figures 1 and 2 plot the conditional distributions for persons living in welfare agencies with $Z_{j}=1$ and persons living in welfare agencies with $Z_{j}=0$. Independently of the instrumental variable chosen, it becomes obvious that for both groups the distributions are almost identical, indicating that the chosen instruments are as good as randomly assigned across subpopulations and provide a valid means to identify causal effects.

In addition, as can be seen from Additional file 1: Figure S2, agencies that sanction frequently and agencies that do not appear to be distributed more or less randomly across the sampled regions. In many cases, agencies that sanction frequently and non-frequently directly border each other. In the city of Berlin, for example, five welfare agencies are sampled. Two of them use sanctions frequently, while three do not. Since Berlin can be

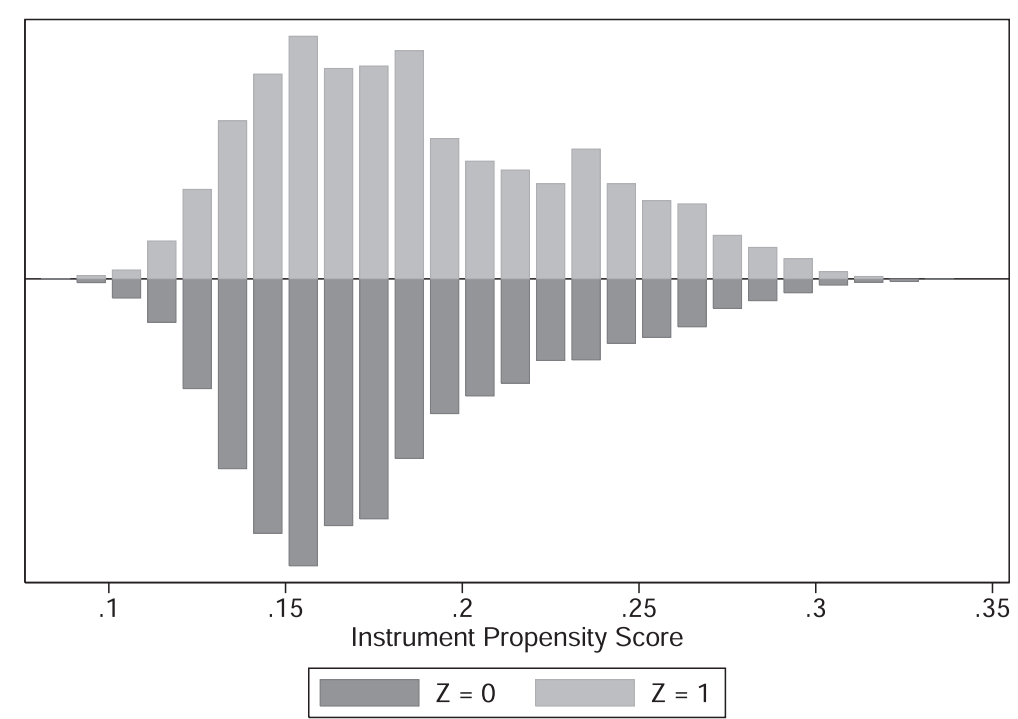

Figure 1 Instrument propensity score for $Z_{1}$. 


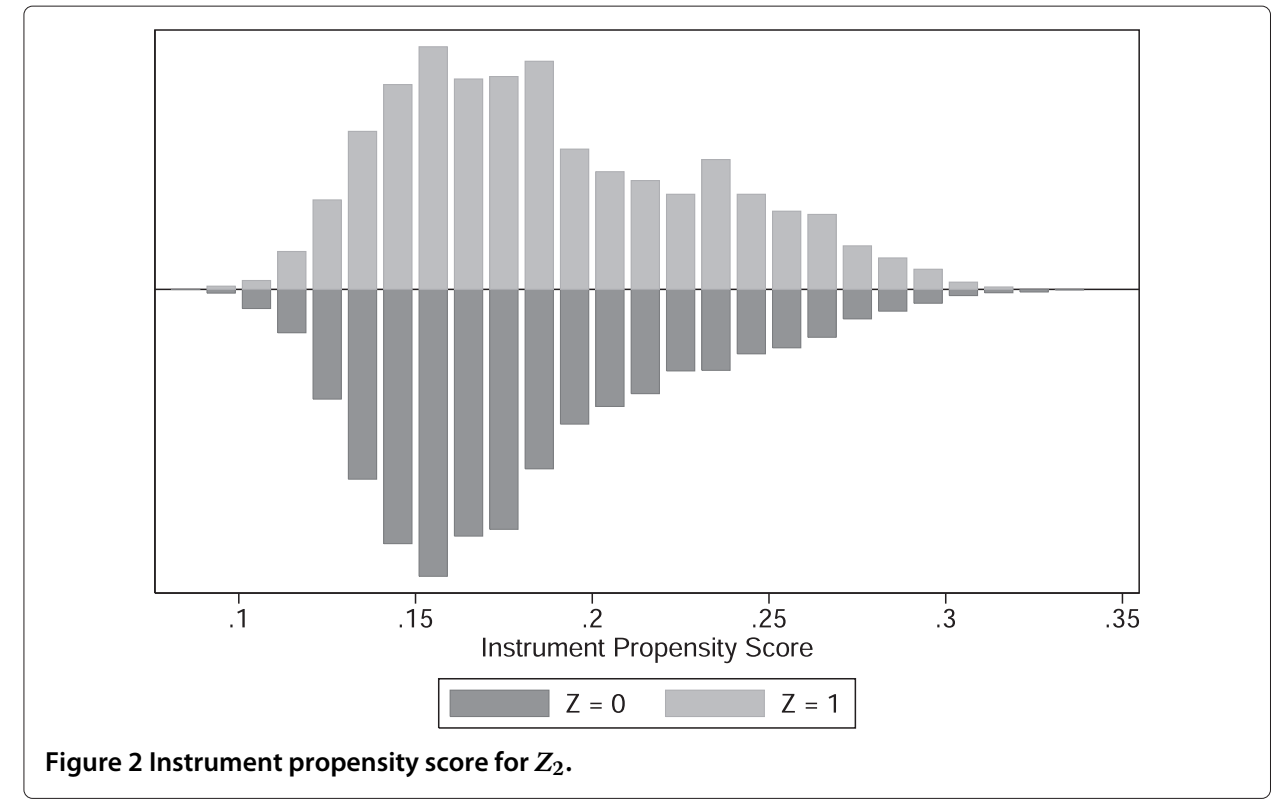

regarded as a single labor market, which is identical for all five agencies within the city, and since the composition of UBII recipients in these five agencies is quite similar, it is unlikely that the sanction strategy of an agency depends on the labor market state or the sociodemographic characteristics of the UBII recipients. A similar picture arises with respect to the actually observed sanction rates within the agencies (see Additional file 1: Figure S3).

To support the argumentation that sanction strategy or aggregate sanction rate are independent of local economic performance or the set-up of the activation process in general, we have regressed both instruments $Z_{1}$ and $Z_{2}$ on

1. a characterization describing the organizational set-up of the counseling process,

2. a number of regional variables intended to characterize the economic performance of the local labor market and

3. both.

Here, the counseling process is classified into four categories, where the main categories 1 and 2 distinguish between a specialized and a generalized kind of case management. In the first type, case managers specialize in counseling certain groups of UBII recipients, for example lone mothers, migrants and young UBII recipients. In the second type, case managers counsel all UBII recipients without distinction. The subcategories $a$ and $b$ denote whether placement in the labor market is part of the case management process or not. Subcategory $a$ denotes that it is not integrated and therefore conducted by other staff of the agency. In subcategory $b$, case managers are also responsible for placement questions. The regional variables include dummy variables for city districts, East Germany, the unemployment ratio, GDP and the welfare ratio as described in the data section. The corresponding regression results (see Additional file 1: Table S1) can be interpreted as correlations between the instruments and local labor market conditions or organizational aspects that both affect the transition to employment. However, since none of the 
estimated coefficients is statistically significant, this can be interpreted in support of the required orthogonality of the instruments from factors relevant for job finding, i.e. neither sanction strategy nor actual sanction rates at the local level systematically depend on economic performance or the organizational set-up of the counseling process.

Moreover, we have regressed the instruments $Z_{1}$ and $Z_{2}$ on two variables reflecting the caseload of welfare agencies (see Additional file 1: Table $S 2$ ). The first variable relates the number of UBII recipients registered at an agency to the full-time equivalent number of overall staff in that agency. The second variable measures the ratio of UBII recipients to the full-time equivalent number of agency staff responsible for labor market activation or case management. Neither of the two coefficient estimates indicate, that a high or low caseload causes the welfare agency to adopt a certain sanction approach.

Finally, we have checked the relationship between our instruments and other strategic features of welfare agencies. In addition to the sanction strategy, the surveys conducted at the agency level asked agency managers how important other activation elements are for the strategy of their welfare agency. These activation elements include job creation schemes, start-up subsidies, wage subsidies for employees and employers, the promotion of professional qualifications, training of key skills for the activation process (like, for example, job search training and internships), the support of disadvantaged young or disabled UBII recipients, the supply of counseling services, the supply of child care facilities and the supply of other social services. For each element, managers could answer on a Likert scale from 1 (not important) to 5 (very important). We use this information to define a variable for each element, distinguishing between agencies for which the respective element has a high strategic value and agencies for which this is not the case. The distinction between the agencies is done at the median level of managers' answers. When regressing $Z_{1}$ and $Z_{2}$ on these variables, we find no indication that the sanction approach of a welfare agency is systematically related to other strategic considerations (see Additional file 1: Table S3 and Table S4). Given all this evidence, we conclude that both $Z_{1}$ and $Z_{2}$ satisfy all requirements to be valid instruments for the identification of the LATEs we want to estimate via Equations (1) and (2).

\section{Empirical results}

\subsection{Descriptive evidence}

Before we present and discuss the estimation results, we provide some descriptive statistics on the sanction strategy $\left(Z_{1}\right)$ and the actually observed sanction rates $\left(Z_{2}\right)$

Table 2 Description of the instruments: sanction strategy and sanction rate ${ }^{(a)}$

\begin{tabular}{cccccc}
\hline & \multicolumn{5}{c}{ Full sample } \\
\cline { 2 - 3 } & \multicolumn{5}{c}{$\mathbf{4 . 3 4 \%}$} \\
\cline { 2 - 3 } & $Z_{\mathbf{1}=\mathbf{0}} \mathbf{Z _ { 1 } = \mathbf { 1 }}$ & & $\mathbf{Z}_{\mathbf{2}}=\mathbf{0}$ & $Z_{\mathbf{2}}=\mathbf{1}$ \\
\cline { 2 - 4 } & $\mathbf{4 . 0 1 \%}$ & $\mathbf{5 . 7 5 \%}$ & & $\mathbf{1 . 8 9 \%}$ & $\mathbf{6 . 5 4 \%}$ \\
\hline Sanctioned & 500 & 167 & & 137 & 530 \\
Non-sanctioned & 11,957 & 2,737 & & 7,121 & 7,573 \\
Total observations & & & 15,361 & &
\end{tabular}

${ }^{a}$ Remarks: $Z_{1}$ refers to the sanction strategy of welfare agencies. $Z_{1}=0$ denotes less strict agencies and $Z_{1}=1$ denotes frequently sanctioning agencies. $Z_{2}$ refers to the actually observed sanction rates within welfare agencies. $Z_{2}=0$ denotes agencies with a sanction rate below the median and $Z_{2}=1$ denotes agencies with a sanction rate above the median. 
in Table 2. The agency strategy of applying sanctions frequently is indeed highly correlated with the imposition of sanctions as reported by the individuals in the survey. While in the full sample comprising all 154 welfare agencies $4.34 \%$ of the UBII recipients were sanctioned between October 2006 and April 2007, the sanction rate is significantly larger for agencies that apply sanctions frequently as part of their activation strategy. Within these agencies, the sanction rate amounts to $5.75 \%$, compared to $4.01 \%$ in the remaining agencies. This difference is remarkable, since the two variables considered are measured at different levels and the sanction strategy varies at the agency level only. The difference is even larger when we look at the actually observed sanction rates. In agencies with a sanction rate above the median, $6.54 \%$ of UBII recipients received a sanction, while for the other agencies we observe a sanction rate of $1.89 \%$ only. Given these differences, both, $Z_{1}$ and $Z_{2}$, can be perceived to fulfill the second condition to identify a LATE: The probability of being sanctioned changes with the value of the instrument.

Table 3 compares means of the variables used as covariates in the econometric analysis for sanctioned and for non-sanctioned individuals and for those individuals registered at agencies that frequently impose sanctions and for individuals registered at all other agencies. In addition, $p$-values of $t$-tests on the equality of means are displayed to allow for a meaningful discussion of differences. Male, younger and less qualified individuals are most likely to have a benefit sanction imposed on them. Moreover, singles, and, to a lesser degree, individuals without children are relatively frequently subject to sanctions. Disabled persons and those with care obligations are less likely to receive a sanction. There are also regional differences in sanction probabilities. In East Germany, fewer sanctions are imposed compared to West Germany. However, no significant differences in sanction probabilities exist with respect to the share of UBII recipients in a region.

The middle part of Table 3 clearly shows that agencies with different sanction strategies are quite similar with respect to the composition of their clients. Only small differences are apparent concerning schooling achievement, household composition and migration status. Slightly more singles, persons without children and persons with the lowest school leaving certificate (secondary general school) are registered at agencies that frequently impose sanctions than at the other agencies. Migrants are somewhat under-represented. More important differences exist with respect to regional characteristics. In rural areas, agencies seem to impose fewer sanctions than in urban districts. For East Germans, the probability of being registered at an agency with a tough sanction policy is a little higher than for West Germans. No clear picture arises with respect to the macroeconomic variables. While agencies that apply sanctions frequently are over-represented in regions with a high welfare-to-population ratio, almost no difference exists with respect to the unemployment ratio. We do not detect any statistically significant difference with respect to GDP, either. Thus, the labor market state does not seem to determine the sanction strategy of an agency, as is required for a strategy in order to be a valid instrument. Nevertheless, the descriptive analysis indicates, that regional variables should be considered in the estimation of the effect of benefit cuts. This is also true when using instrument $Z_{2}$. As can be seen from the right-hand side of Table 3, differences between agencies with $Z_{2}=0$ and $Z_{2}=1$ are somewhat larger than between agencies with $Z_{1}=0$ and $Z_{1}=1$. 
Table 3 Descriptive statistics ${ }^{(a)}$

\begin{tabular}{|c|c|c|c|c|c|c|c|c|c|}
\hline & $S=0$ & $S=1$ & $p$-val. & $Z_{1}=0$ & $z_{1}=1$ & $p$-val. & $z_{2}=0$ & $z_{2}=1$ & $p$-val. \\
\hline \multicolumn{10}{|l|}{ Gender } \\
\hline Male & 0.459 & 0.565 & 0.000 & 0.464 & 0.464 & 0.973 & 0.465 & 0.463 & 0.821 \\
\hline \multicolumn{10}{|l|}{$\overline{\text { Age }}$} \\
\hline $18-24$ & 0.203 & 0.381 & 0.000 & 0.210 & 0.217 & 0.422 & 0.209 & 0.213 & 0.469 \\
\hline $25-34$ & 0.207 & 0.258 & 0.002 & 0.209 & 0.208 & 0.863 & 0.205 & 0.213 & 0.264 \\
\hline $35-44$ & 0.211 & 0.174 & 0.023 & 0.209 & 0.207 & 0.798 & 0.210 & 0.208 & 0.726 \\
\hline $45-57$ & 0.379 & 0.187 & 0.000 & 0.371 & 0.368 & 0.751 & 0.376 & 0.366 & 0.208 \\
\hline \multicolumn{10}{|l|}{ Schooling } \\
\hline Secondary general school & 0.443 & 0.505 & 0.001 & 0.441 & 0.466 & 0.013 & 0.412 & 0.475 & 0.000 \\
\hline Intermediate secondary school & 0.338 & 0.262 & 0.000 & 0.338 & 0.319 & 0.045 & 0.376 & 0.297 & 0.000 \\
\hline University entrance diploma & 0.160 & 0.123 & 0.010 & 0.160 & 0.154 & 0.467 & 0.156 & 0.161 & 0.332 \\
\hline Other or missing & 0.059 & 0.109 & 0.000 & 0.061 & 0.061 & 0.939 & 0.056 & 0.066 & 0.006 \\
\hline \multicolumn{10}{|l|}{ Migration background } \\
\hline Migrant & 0.247 & 0.258 & 0.539 & 0.252 & 0.231 & 0.018 & 0.223 & 0.270 & 0.000 \\
\hline \multicolumn{10}{|l|}{ Household size } \\
\hline 1 person & 0.345 & 0.402 & 0.003 & 0.341 & 0.376 & 0.000 & 0.323 & 0.370 & 0.000 \\
\hline 2 persons & 0.278 & 0.229 & 0.006 & 0.280 & 0.257 & 0.011 & 0.295 & 0.258 & 0.000 \\
\hline 3 or more persons & 0.377 & 0.369 & 0.666 & 0.379 & 0.367 & 0.233 & 0.383 & 0.371 & 0.155 \\
\hline \multicolumn{10}{|l|}{ Number of children } \\
\hline No children & 0.611 & 0.651 & 0.040 & 0.609 & 0.629 & 0.040 & 0.610 & 0.615 & 0.548 \\
\hline 1 child & 0.214 & 0.201 & 0.425 & 0.216 & 0.203 & 0.140 & 0.223 & 0.205 & 0.006 \\
\hline 2 or more children & 0.175 & 0.148 & 0.075 & 0.176 & 0.167 & 0.293 & 0.167 & 0.180 & 0.030 \\
\hline \multicolumn{10}{|l|}{ Obstacles to employment } \\
\hline Disabled person & 0.105 & 0.054 & 0.000 & 0.103 & 0.101 & 0.766 & 0.098 & 0.106 & 0.119 \\
\hline Care obligation & 0.033 & 0.019 & 0.055 & 0.033 & 0.030 & 0.488 & 0.035 & 0.030 & 0.065 \\
\hline \multicolumn{10}{|l|}{ Status before receipt of welfare benefits } \\
\hline (Minor) employment & 0.322 & 0.396 & 0.000 & 0.326 & 0.325 & 0.943 & 0.319 & 0.331 & 0.109 \\
\hline \multicolumn{10}{|c|}{ Number of previous unemployment spells } \\
\hline 0 or 1 & 0.389 & 0.370 & 0.340 & 0.387 & 0.393 & 0.541 & 0.391 & 0.385 & 0.418 \\
\hline 2 or 3 & 0.370 & 0.379 & 0.624 & 0.373 & 0.358 & 0.130 & 0.364 & 0.376 & 0.150 \\
\hline 4 or more & 0.183 & 0.196 & 0.384 & 0.183 & 0.187 & 0.606 & 0.188 & 0.180 & 0.209 \\
\hline Missing & 0.058 & 0.054 & 0.644 & 0.057 & 0.062 & 0.317 & 0.056 & 0.059 & 0.428 \\
\hline \multicolumn{10}{|l|}{ Regional information } \\
\hline City district & 0.300 & 0.337 & 0.040 & 0.289 & 0.355 & 0.000 & 0.283 & 0.318 & 0.000 \\
\hline East Germany & 0.253 & 0.153 & 0.000 & 0.244 & 0.267 & 0.009 & 0.369 & 0.140 & 0.000 \\
\hline Unemployment ratio (high) & 0.255 & 0.160 & 0.000 & 0.247 & 0.263 & 0.074 & 0.366 & 0.147 & 0.000 \\
\hline GDP (high) & 0.286 & 0.361 & 0.000 & 0.291 & 0.280 & 0.216 & 0.209 & 0.360 & 0.000 \\
\hline Welfare ratio (high) & 0.284 & 0.289 & 0.779 & 0.276 & 0.323 & 0.000 & 0.281 & 0.287 & 0.404 \\
\hline \multicolumn{10}{|l|}{ Current welfare spell } \\
\hline Months in welfare before $10 / 2006$ & 12,437 & 10,927 & 0.000 & 12,356 & 12,440 & 0.660 & 12.806 & 11.982 & 0.000 \\
\hline Start after $10 / 2006$ or missing & 0.183 & 0.178 & 0.774 & 0.186 & 0.170 & 0.047 & 0.183 & 0.182 & 0.912 \\
\hline Observations & 14,694 & 667 & 15,361 & 12,457 & 2,904 & 15,361 & 7,258 & 8,103 & 15,361 \\
\hline
\end{tabular}


Table 4 displays the mean employment rates for the first six months after the (hypothetical) sanction date. It distinguishes between sanctioned and non-sanctioned individuals registered either at agencies that frequently impose sanctions or at agencies that do not. The share of persons taking up employment and thereby leaving the welfare system increases over time in all subgroups. For example, 5.91\% of the non-sanctioned persons who are registered at agencies that do not follow a tough sanction strategy $\left(Z_{1}=0\right)$ have left the welfare system for employment one month after the (hypothetical) sanction date. This share increases steadily and amounts to $10.59 \%$ six months after the (hypothetical) sanction. For the sanctioned group in the same agencies, the outflow rate rises from $2.60 \%$ to $8.80 \%$. When looking at agencies that frequently impose sanctions $\left(Z_{1}=1\right)$, the increase in the employment probability of sanctioned individuals is even more pronounced. Outflow rates start at $2.40 \%$ in the first month and rise to more than $20 \%$ in the final month of the observation period. For the alternative instrument $Z_{2}$ and individuals who are sanctioned in agencies with a sanction rate above the median $\left(Z_{2}=1\right)$, we observe a more modest increase in employment rates from $2.45 \%$ to $12.26 \%$. Nevertheless, as in the case of $Z_{1}$, this subgroup has the largest employment share at the end of the observation period.

\subsection{Estimation results}

Before turning to the estimates of the LATE, we will discuss the first stage regression results (see Additional file 1: Table S5 for the corresponding coefficient estimates). The instrument $Z_{1}$ (sanction strategy) has a significantly positive effect on the sanction probability. Individuals registered at agencies that frequently impose sanctions have a 2.86 percentage point higher probability of getting a sanction than individuals registered at the other agencies. Given the low average sanction rate on average, this is a large effect. The effect is also large in absolute terms, when compared to the coefficients of the other covariates included in the model. The $F$-statistic for significance of the instrument $Z_{1}$ in the first stage regression is 10.64. It is thus close to the threshold value of 10 suggested by 1997 to indicate a potential weak instrument problem. ${ }^{11}$ To investigate whether a weak

Table 4 Description of the outcome variable self-sufficient employment

\begin{tabular}{|c|c|c|c|c|c|c|c|c|}
\hline & \multicolumn{4}{|c|}{$Z_{1}$} & \multicolumn{4}{|c|}{$Z_{2}$} \\
\hline & \multicolumn{2}{|c|}{$Z_{1}=0$} & \multicolumn{2}{|c|}{$Z_{1}=1$} & \multicolumn{2}{|c|}{$Z_{2}=0$} & \multicolumn{2}{|c|}{$Z_{2}=1$} \\
\hline & $S=0$ & $S=1$ & $S=0$ & $S=1$ & $S=0$ & $S=1$ & $S=0$ & $S=1$ \\
\hline \multicolumn{9}{|c|}{ Month } \\
\hline 1 & 0.0591 & 0.0260 & 0.0617 & 0.0240 & 0.0524 & 0.0292 & 0.0664 & 0.0245 \\
\hline 2 & 0.0648 & 0.0460 & 0.0745 & 0.0479 & 0.0588 & 0.0511 & 0.0739 & 0.0453 \\
\hline 3 & 0.0736 & 0.0560 & 0.0811 & 0.0898 & 0.0653 & 0.0511 & 0.0841 & 0.0679 \\
\hline 4 & 0.0840 & 0.0640 & 0.0891 & 0.1257 & 0.0729 & 0.0657 & 0.0964 & 0.0830 \\
\hline 5 & 0.0965 & 0.0740 & 0.1023 & 0.1677 & 0.0829 & 0.0876 & 0.1114 & 0.1000 \\
\hline 6 & 0.1059 & 0.0880 & 0.1155 & 0.2036 & 0.0932 & 0.0949 & 0.1212 & 0.1226 \\
\hline
\end{tabular}

Remarks: The outcome variable is defined to be 1 if an individual is employed and does not receive welfare benefits anymore. Otherwise, the variable is 0 . The variable is displayed for the first six months after the (hypothetical) sanction date. $S=0$ denotes non-sanctioned individuals, and $S=1$ denotes sanctioned individuals. $Z_{1}$ refers to the sanction strategy of welfare agencies. $Z_{1}=0$ denotes less strict agencies, and $Z_{1}=1$ denotes frequently sanctioning agencies. $Z_{2}$ refers to the observed sanction rates within welfare agencies. $Z_{2}=0$ denotes welfare agencies with a sanction rate below the median across all 154 sampled agencies, and $Z_{2}=1$ denotes agencies with a sanction rate above the median. 
instrument problem is in fact present, we use the second instrument $Z_{2}$, which differentiates between agencies with a sanction rate above and below the median level. In this case, we estimate an even larger impact on the individual sanction probability in the first stage regression. The coefficient of the instrument $Z_{2}$ is highly significant and amounts to 4.78 percentage points. The $F$-statistic is 122.09 and thus considerably larger than the threshold value. Therefore, besides giving further insight into the effectiveness of sanctions, $Z_{2}$ also allows us to assess how precisely the sanction effect is estimated using instrument $Z_{1}$.

Based on $Z_{1}$, the upper part of Table 5 provides the estimation results for the LATE of a sanction on employment in the first six months after the (hypothetical) benefit cut. The positive coefficients of the sanction variable reveal that the outflow from welfare to employment increases due to an imposed sanction, even after controlling for a number of individual and regional characteristics. ${ }^{12}$ During the first three months, the effect is modest and not statistically significant. In the fourth month, we observe a large increase in the outflow rate. The effect becomes statistically significant in the fifth month and amounts to 0.6766 at the end of the observation period. This figure indicates that a benefit cut induced by a change of the sanction regime increases the probability that affected individuals will leave the welfare system within six months after the benefit cut by nearly 68 percentage points. It thus constitutes a considerable sanction effect.

Considerable effects of benefit sanctions have also been identified in the relevant empirical literature for other countries. Van den Berg et al. (2004), for example, find that the probability of an average 25-year-old Dutch welfare recipient in the city of Rotterdam of leaving the welfare system within two years increases from $66 \%$ to $91 \%$ if a sanction is imposed after 6 months of being on welfare. For a 50-year-old, the corresponding probability increases from $29 \%$ to $54 \%$. Focusing on the same labor market but a more recent time period, van der Klaauw and van Ours (2013) estimate increases in the exits rates of $21 \%$ for males and $47 \%$ for females. They explain the reduction in effects compared to van den Berg et al. (2004) by a more intensive use of sanctions in the period of analysis. Similar high levels of the effects of benefit sanctions are found by Abbring et al. (2005): they report increases in the re-employment rates of males by up to $61 \%$ and even by $98 \%$ for females in the metal industry. Comparable to that, Lalive et al. (2005) analyzing the

Table 5 Estimated sanction effects

\begin{tabular}{ccccccc}
\hline Month & $\mathbf{1}$ & $\mathbf{2}$ & $\mathbf{3}$ & $\mathbf{4}$ & $\mathbf{5}$ & $\mathbf{6}$ \\
\hline Sanction & 0.0092 & 0.1347 & 0.1689 & 0.4475 & $0.5604^{*}$ & $0.6766^{* * *}$ \\
(based on $\left.Z_{1}\right)$ & $(0.2015)$ & $(0.2383)$ & $(0.2436)$ & $(0.2795)$ & $(0.2927)$ & $(0.2607)$ \\
& & & & & \\
Sanction & $0.2802^{* *}$ & $0.2402^{* *}$ & $0.3594^{* * *}$ & $0.4496^{* * *}$ & $0.4950^{* * *}$ & $0.5802^{* * *}$ \\
(based on $\left.Z_{2}\right)$ & $(0.1124)$ & $(0.1216)$ & $(0.1249)$ & $(0.1353)$ & $(0.1437)$ & $(0.1396)$ \\
\hline Observations & \multicolumn{7}{c}{15,361} \\
\hline
\end{tabular}

Remarks: The upper part of the table refers to the estimation in which $Z_{1}$ (sanction strategy of welfare agencies) is used as instrument; the lower part of the table refers to the estimation in which $Z_{2}$ (observed sanction rates within welfare agencies) is used as instrument. The dependent variable in each estimation and for each month is defined to be 1 if an individual is employed and no longer receives welfare benefits. Otherwise, the variable is 0 . Displayed are the estimated sanction effects and standard errors in brackets. The results refer to the first six months after the (hypothetical) sanction date. ${ }^{* * *}$ denotes $p<0.01,{ }^{* *}$ denotes $p<0.05$, and $*$ denotes $p<0.1$. The standard errors take into account clustering at the agency level. Detailed estimation results for $Z_{1}$ and $Z_{2}$ including all covariates are displayed in Additional file 1: Table S6 and Table S7. 
effects of benefit sanctions in Switzerland estimate an increase in the exit rate to employment by $45 \% ; 25.2 \%$ of the effect results from the ex-ante effect (the effect of the warning to get sanctioned) and $19.8 \%$ from the ex-post effect of the actually imposed sanction. In a follow-up study, Arni et al. (2013) confirm these findings: they report an increase in unemployment exit by $31.9 \%$ (with $15.9 \%$ attributed to the effect of a warning) but more importantly an increase of the exit rate to non-employment by $116.0 \%$.

Since we estimate the LATE, the level of the identified effects is in line with expectations. The LATE depicts the effect for those, who get sanctioned after a tightening of the sanction policy in the welfare agency. It can thus be interpreted as an estimate of the effect of an intensified use of sanctions. In contrast to looking at the effect of a sanction for the average welfare recipient (who is in focus in other empirical studies), we estimate the sanction effect for a more narrowly defined group of persons. Our results show that this subgroup, which has not been regarded in the literature so far, reacts even stronger to sanctions than existing studies found for average sanctioned individuals. Therefore, we conclude that intensifying the use of sanctions is an effective tool to increase employment.

The estimated effects, however, suffer from large standard errors. We therefore use instrument $Z_{2}$ to check for robustness. As can be seen from the lower part of Table 5, the results based on this instrument reveal a similar effectiveness of sanctions as obtained by using instrument $Z_{1}$, but results are more precisely estimated as reflected by the lower standard errors ${ }^{13}$. Again, we observe an increasing sanction effect during the observation period. In the first three months, the estimated effects are larger than in the case of $Z_{1}$ and already statistically significant. At the end of the observation period, the effects are somewhat lower compared with $Z_{1}$, but highly significant. Six months after the (hypothetical) benefit cut, the probability of taking up employment for a welfare recipient who is at risk of being sanctioned increases by about 58 percentage points $(0.5802)$, when the welfare agency decides to increase the sanction rate from below to above the median level, thereby imposing a sanction on the individual. The effect is in the same range as the effect measured by instrument $Z_{1}$. Given the similarity of the estimates between the two instrumental variables, we conclude that our estimation approach does not suffer from a weak instrument problem. The sanction effect is of considerable size.

The smaller size of the coefficient for the treatment variable after six months in the estimation approach using $Z_{2}$ rather than $Z_{1}$ as the instrumental variable is not necessarily due to the lower empirical variation in the instrumental variable. The LATE is identified only for the so-called compliers, who receive a sanction, when the instrument changes its value from 0 to 1 . Having defined two different instruments, we also consider two different groups of compliers. One group is affected by a change in the sanction strategy of the welfare agency, whereas the other is affected by a change in the observed sanction rate. Since both groups are not identical, it cannot be expected that the estimated LATEs are identical.

\subsection{Robustness checks}

In addition to the empirical estimates presented above, we have also estimated a number of models in order to check the robustness of the findings. A first issue considered refers to the specification of the first stage regressions. Additional file 1: Table S8 and Table S9 provide coefficient estimates of five further model specifications. 
These specifications differ with respect to the inclusion of labor market history information, regional information and information regarding individual's qualification. The results indicate that the coefficient estimates of the instrumental variables are consistently estimated and are almost identical across the different model specifications.

Corresponding results for the second stage regressions are reported in Additional file 1: Table S10 and Table S11. The point estimates of the treatment effects differ slightly across specifications, but are of comparable magnitude and significance. All estimates indicate a substantial sanction effect, further supporting the validity of the chosen instruments.

Another robustness check conducted regards the hypothetical sanction dates. Alternatively to using a uniform distribution, we constructed hypothetical sanction dates for the non-sanctioned individuals by imaging the observed distribution of sanction dates among the sanctioned individuals. In our sample, $11.54 \%$ of all sanctions were imposed in October 2006, 8.25\% in November 2006, 21.14\% in December 2006, 26.84\% in January 2007, 19.19\% in February 2007, 10.94\% in March 2007, and 2.10\% in April 2007. When randomly assigning hypothetical sanction dates according to this distribution to the non-sanctioned individuals, our estimation results confirm a sanction effect as substantial as in the case of a uniform distribution of hypothetical sanction dates.

\section{Conclusion}

Recent studies investigating the effect of sanctions imposed on unemployment insurance benefit and welfare benefit recipients show that benefit cuts substantially increase employment uptake among the sanctioned persons. This evidence at the individual level raises the question whether welfare agencies should intensify the use of sanctions to decrease welfare dependency rates and to increase employment rates on a larger scale. To answer this question, we estimate the effect of a sanction on those individuals who receive a benefit cut if their welfare agency decides to tighten its sanction regime. This effect has not been analyzed in the literature so far.

We use a unique data set for Germany. The data set shows that benefit sanctions are not imposed uniformly, when an individual does not comply with his or her duties during the activation process. Rather, there is substantial discretion at the agency level determining whether a sanction is applied or not. While some agencies frequently impose sanctions, the policy of others is less tough. We use these differences in sanction strategies and rates across 154 welfare agencies in Germany as instrumental variables to estimate the effect of a benefit cut on the individual employment probability. Specifically, we estimate the effect of a sanction on those individuals who are not sanctioned by an agency with a cautious sanction policy, but who would be sanctioned if the agency decided to impose sanctions more frequently. This LATE can be interpreted as an estimate of the effectiveness of an intensified use of sanctions.

Our results show that the intensified use of sanctions can be quite effective in increasing employment rates. A sanction increases the probability of the affected compliers to leave the welfare system for employment within six months after the benefit cut by 58 to 68 percentage points. Therefore, we conclude that a more intensive use of benefit cuts by 
welfare agencies can contribute to making the labor market activation of UBII recipients more effective by increasing the transition rate from welfare to work.

\section{Endnotes}

${ }^{1}$ Compact overviews of a number of different unemployment insurance systems of selected OECD countries with consideration of benefit sanctions are provided by Grubb (2000) and Venn (2012).

${ }^{2}$ Most studies concentrate on unemployment insurance benefit recipients, but there also exists some evidence for welfare recipients. For studies analyzing the effects on unemployment benefit recipients see, for example, Abbring et al. (2005) for the Netherlands, Lalive et al. (2005) and Arni et al. (2013) for Switzerland, Svarer (2011) for Denmark, or Müller and Steiner (2008) and Hofmann (2012) for Germany. Empirical analyses for welfare recipients are provided by van den Berg et al. (2004) for the Netherlands, Grogger and Karoly (2005) or Blank and Haskins (2001) for the US, besides others.

${ }^{3}$ This regional variation in sanction rates is not specific to Germany, but has been reported in the literature as well. For example, Lalive et al. (2005) report different sanction intensities across Swiss cantons.

${ }^{4}$ The exploitation of regional information within an instrumental variable setting for the evaluation of labor market policies has recently also been suggested by Frölich and Lechner (2010).

${ }^{5}$ At the beginning of 2005, UBII cash payments amounted to EUR 345 in West Germany and to EUR 331 in East Germany. Meanwhile, the level of UBII in East Germany was adjusted to the Western level and UBII was slightly raised in both parts to compensate for inflation.

${ }^{6}$ We excluded 811 persons with more than one sanction, 989 individuals with a sanction before the sampling date, 181 UBII recipients with a sanction in a former UBII spell and 489 observations with missing information.

${ }^{7}$ We dropped 845 individuals aged 15 to $17,2,116$ persons aged 58 to 64 and 3,771 UBII recipients who are employed.

${ }^{8}$ In some cases, UBII recipients appeal against the imposition of a sanction. Social courts then have to decide on the legitimacy of the sanction. The average duration of litigations in these instances was 13.7 months in 2007 (see Statistisches Bundesamt 2009). This period is considerably longer than our observation period of six months after the (hypothetical) imposition of the sanction. Therefore, we do not expect that a potential appeal of sanctioned survey participant against the benefit cut affects his or her behavior in our observation window. Since the sanction is in force despite the appeal, there is the same incentive to increase job search effort as in the case without an appeal.

${ }^{9}$ Figures according to the German Federal Statistical Office and the FEA.

${ }^{10}$ In this specification, we control for sex, age, schooling, migration background, household size, number of children, obstacles to employment, labor market status before welfare receipt, previous unemployment spells, regional information and the duration of the current welfare spell. The duration of the welfare spell is measured as the number of months on benefits before the sampling date. Due to the time span between sampling and interview date, not all individuals report a starting date of welfare receipt before the sampling date. Some left and re-entered the welfare system during fall and winter 2006/2007 and thus report a starting date after the sampling date. For these individuals the duration variable is set to 0 . An additional dummy variable takes these late starting dates into account.

${ }^{11}$ We rely on this rule of thumb since we cannot apply the tests proposed by Stock and Yogo (2005) because we use only one instrument and do not assume homoscedastic errors but allow for clustering at the agency level. 
${ }^{12}$ Additional file 1: Table S6 depicts the detailed estimation results including all considered covariates.

${ }^{13}$ Detailed results including all considered covariates are displayed in Additional file 1: Table S7.

\section{Additional file}

Additional file 1: Appendix. Table S1. Regression of $Z_{1}$ and $Z_{2}$ on organizational and regional variables. Table S2. Regression of $Z_{1}$ and $Z_{2}$ on caseload variables. Table S3. Regression of $Z_{1}$ on strategical variables. Table S4. Regression of $Z_{2}$ on strategical variables. Table $\mathbf{S 5}$. First stage results based on instruments $Z_{1}$ and $Z_{2}$. Table S6. Detailed estimation results for sanction effects based on instrument $Z_{1}$. Table S7. Detailed estimation results for sanction effects based on instrument $Z_{2}$. Table S8. Sensitivity analysis for the first son based on instrument $Z_{1}$. Table S9. Sensitivity analysis for the first stage regression based on instrument $Z_{2}$. Table S10. Sensitivity analysis for the second stage regression based on instrument Z1 in month 6. Table S11. Sensitivity analysis for the second stage regression based on instrument Z2 in month 6. Figure S1. Sampled agencies. Figure S2. Sanction strategies. Figure S3. Sanction rates.

\section{Competing interests}

The IZA Journal of Labor Policy is committed to the IZA Guiding Principles of Research Integrity. The authors declare that they have observed these principles.

\section{Acknowledgements}

The authors wish to thank an anonymous referee, Veronica Amarante, Bernd Fitzenberger, Markus Frölich, Christina Gathmann, David Grubb, Olaf Hübler, and Jeff Smith for valuable comments. The paper has benefited from discussions at the Conference of the European Society for Population Economics in Seville, 2009, the Conference of the Canadian Economic Association in Toronto, 2009, the Conference of the European Association of Labour Economists in Tallinn, 2009, the XXIV National Conference of Labour Economics (AIEL) in Sassari, 2009, the Workshop of the German Statistical Society in Merseburg, 2009, the Royal Economic Society Annual Conference, 2010, the Workshop "Monitoring, Counseling and Sanctions: Structural and Reduced Form Evaluation" at Ghent University and UC Leuven, 2010, and seminars at ZEW Mannheim, RWI Essen, the University of Michigan, and Leibniz Universität Hannover. The paper is based on results of the project "Evaluation of the Experimentation Clause in $\S 6$ C SGB II" commissioned by the Federal Ministry of Labor and Social Affairs (BMAS). The data base for this study originated from a joint effort of ZEW Mannheim with IAB Nuremberg, TNS Emnid Bielefeld and IAQ Gelsenkirchen to merge administrative and survey data to evaluate the effects of Germany's 2005 welfare reform. Stephan Thomsen thanks the Stifterverband für die Deutsche Wissenschaft (Claussen-Simon-Stiftung) for financial support. The usual disclaimer applies.

Responsible editor: Juan F. Jimeno.

\section{Author details}

${ }^{1}$ Institute for Applied Economic Research (IAW), Ob dem Himmelreich 1, D-72074, Tübingen, Germany. ${ }^{2}$ Universität Tübingen, Tübingen, Germany. ${ }^{3}$ IZA, Bonn, Germay. ${ }^{4}$ NIW Hannover, Königstr. 53, D-30175 Hannover, Germany. ${ }^{5}$ Leibniz Universität Hannover, Hannover, Germany. ${ }^{6}$ ZEW, Mannheim, Germany. ${ }^{7}$ Centre for European Economic Research (ZEW), L7, 1, D-68161 Mannheim, Germany.

Received: 5 February 2014 Accepted: 19 August 2014 Published: 08 Oct 2014

\section{References}

Abbring J, van den Berg G, van Ours J (2005) The effect of unemployment insurance sanctions on the transistion rate from unemployment to employment. Econ J 115:602-630

Arni P, Lalive R, van Ours J (2013) How effective are unemployment benefit sanctions? Looking beyond unemployment exit. J Appl Econometrics 28(7):1153-1178

Baethge-Kinsky V, Bartelheimer P, Henke J, Wolf A, Land R, Willisch A, Kupka P (2007) Neue soziale Dienstleistungen nach SGB II, IAB Forschungsbericht, 15/2007. IAB, Nuremberg

Blank R, Haskins R (2001) The new world of welfare. Brookings Institution Press, Washington, D.C

Frölich M, Lechner M (2010) Exploiting regional treatment intensity for the evaluation of labour market policies. J Am Stat Assoc 105(491):1014-1029

Grogger J, Karoly L (2005) Welfare reform: effects of a decade of change. Harvard University Press, Cambridge Grubb M (2000) Eligibility criteria for unemployment benefits. OECD Econ Stud 31(2):147-184

Hofmann B (2012) Short- and long-term ex-post effects of unemployment insurance sanctions - evidence from West Germany. Jahrbücher für Nationalökonomie und Statistik 232(1):31-60

Imbens G, Angrist J (1994) Identification and estimation of local average treatment effects. Econometrica 62:467-475

Lalive R, van Ours J, Zweimüller J (2005) The effect of benefit sanctions on the duration of unemployment. J Eur Econ Assoc 3:1386-1417

Müller K-U, Steiner V (2008) Imposed benefit sanctions and the unemployment-to-employment transition - The German experience. Discussion papers 792, DIW, Berlin

Sianesi B (2004) An evaluation of the swedish system of active labor market programs in the 1990s. Rev Econ Stat 86(1):133-155

Staiger D, Stock J (1997) Instrumental variables regression with weak instruments. Econometrica 65:557-586 
Statistisches Bundesamt (2009) Rechtspflege. Sozialgerichte 2007. Fachserie 10 Reihe 2.7. Statistisches Bundesamt, Wiesbaden

Stock J, Yogo M (2005) Testing for weak instruments in linear IV regression. In: Andrews D, Stock J (eds) Identification and inference for econometric models: essays in honor of Thomas Rothenberg. Cambridge University Press, Cambridge, pp 80-108

Svarer M (2011) The effect of sanctions on the exit rate from unemployment: evidence from Denmark. Economica 78(312):751-778

van den Berg G, van der Klaauw B, van Ours J (2004) Punitive sanctions and the transition rate from welfare to work. J Labor Econ 22:211-241

van der Klaauw B, van Ours J (2013) Carrot and stick: how re-employment bonuses and benefit sanctions affect exit rates from welfare. J Appl Econometrics 28(2):275-298

Venn D (2012) Eligibility criteria for unemployment benefits: quantitative indicators for OECD and EU Countries. OECD Social Employment and Migration Working Papers No. 131, OECD Publishing

10.1186/2193-9004-3-21

Cite this article as: Boockmann et al:: Intensifying the use of benefit sanctions: an effective tool to increase employment? IZA Journal of Labor Policy 2014, 3:21

Submit your manuscript to a SpringerOpen ${ }^{\circ}$ journal and benefit from:

- Convenient online submission

- Rigorous peer review

- Immediate publication on acceptance

- Open access: articles freely available online

- High visibility within the field

- Retaining the copyright to your article

Submit your next manuscript at $\gg$ springeropen.com 